\title{
Isótopos estáveis de carbono e oxigênio em ostracodes do Cretáceo: metodologias, aplicações e desafios
}

\author{
Gislaine Bertoglio Rodrigues \\ PPGEO FOSSIL, Univ. do Vale do Rio dos Sinos \\ São Leopoldo-RS, Brasil. \\ gislaine.geo@gmail.com \\ Gerson Fauth \\ ITT FOSSIL, Univ. do Vale do Rio dos Sinos \\ São Leopoldo-RS, Brasil. \\ gersonf@unisinos.br
}

\begin{abstract}
CARBON AND OXYGEN STABLE ISOTOPES IN CRETACEOUS OSTRACODS: METHODOLOGY, APPLICATIONS AND CHALLENGES. Ostracods are important carbonate microfossils in stable isotope study because they occur in different aquatic environments and their carapaces calcify rapidly. The carbon isotopes provide information about paleoproductivity and availability of nutrients in oceans and lakes. Oxygen isotopes are used to estimate paleotemperature and paleosalinity existing in a sedimentary basin, over geologic time. To date, the isotopic analysis on ostracods carapaces are carried out mainly in Cenozoic material, with few researches conducted for Mesozoic. This technique is widely used on ostracods of non-marine environments and used with wariness in transitional and marine environments, where the carapaces composition will be similar to carbonate rock that contains it. This article includes concepts of stable isotopes, the analytical technique used, carrying out analysis on ostracods and interpretation of results in paleoenvironmental studies, and proposes a research protocol considering the difficulties of sampling and application in material from Cretaceous. Citation: Rodrigues B.G., Fauth G. 2013. Isótopos estáveis de carbono e oxigênio em ostracodes do cretáceo: metodologias, aplicações e desafios. Terræ Didatica, 9(1):34-49. <http://www.ige.unicamp.br/terraedidatica/>.
\end{abstract}

KEY WORDS: isotopic analysis, paleoproductivity, paleotemperature, paleo-reconstruction, Cretaceous.

RESUMO Ostracodes são microfósseis carbonáticos que têm se destacado na pesquisa de isótopos estáveis devido à rápida calcificação da carapaça, sua elevada sensibilidade aos parâmetros ambientais e à sua ocorrência em diferentes ambientes aquáticos. Os isótopos de carbono proporcionam informações sobre paleoprodutividade e disponibilidade de nutrientes dos oceanos e lagos. Os isótopos de oxigênio são utilizados para estimar a paleotemperatura e a paleosalinidade vigentes em determinada bacia sedimentar ao longo do tempo geológico. Até o momento, as análises isotópicas em carapaças de ostracodes são realizadas principalmente em material do Cenozoico, com poucas pesquisas realizadas para o Mesozoico. Esta técnica é amplamente utilizada em ostracodes de ambientes não-marinhos, sendo realizada com cautela em ambientes transicionais e marinhos, onde a composição da carapaça será semelhante à da rocha carbonática que o contém. Este texto compreende conceitos de isótopos estáveis, da técnica analítica utilizada, da realização das análises em ostracodes e da interpretação dos resultados nos estudos paleoambientais, e propõe um protocolo de pesquisa considerando as dificuldades de amostragem e de aplicação em carapaças do Cretáceo.

PALAVRAS-CHAVE: análises isotópicas, ostracodes, paleoprodutividade, paleotemperatura, Cretáceo. 


\section{Introdução}

A geoquímica isotópica é uma técnica auxiliar que tem se destacado na interpretação de dados paleontológicos. Nas últimas décadas, as análises de isótopos estáveis têm sido aplicadas em carapaças de ostracodes, por apresentarem grande sensibilidade às variações ambientais e rápida calcificação. Além disso, os ostracodes possuem ampla distribuição em ambientes aquáticos continentais, transicionais e marinhos.

Os ostracodes são pequenos crustáceos bivalves com tamanho variando entre 0.3 e $1.5 \mathrm{~mm}$, que surgiram no Ordoviciano (448 Ma). Seu corpo é protegido por uma carapaça de composição quitino-calcítica formada por reações entre o meio e o próprio organismo. Conforme Bergue (2006), os ostracodes passam por oito estágios de crescimento (instars) durante sua vida e em cada um deles uma nova carapaça é sintetizada, sendo que o carbonato utilizado para sua síntese não é reabsorvido, provindo totalmente da água.

A camada carbonática da carapaça é facilmente fossilizável. Os elementos-traço identificados nas carapaças provêm da própria água e são absorvidos durante a precipitação e formação da carapaça. As análises das razões molares de $\mathrm{Mg} / \mathrm{Ca}$ e $\mathrm{Sr} / \mathrm{Ca}$ permitem estimar a temperatura e a salinidade do ambiente. Também são realizadas análises de outros elementos-traço como $\mathrm{Na}, \mathrm{K}, \mathrm{Al}, \mathrm{Si}$. Fe, Mn, P (Chivas et al. (1983), De Decker et al. (1988), Corrège (1993), Xia et al. (1997a e 1997b), Corrège \& De Decker (1997), Wansard (1999), Boomer (2002), Palacios-Fest et al. (2002), Li et al. 2007 e Zhang et al. (2009)), e de isótopos estáveis, especialmente de carbono, oxigênio e estrôncio. Entretanto, dentre estas análises, os principais indicadores (proxies) da composição da água do mar do passado são os valores isotópicos dos sedimentos químicos e das carapaças precipitadas na água do mar, obtidas pelos valores das razões isotópicas de carbono $\left(\delta^{13} \mathrm{C}\right)$ e de oxigênio $\left(\delta^{18} \mathrm{O}\right)$ (Fischer \& Wefer 1999).

Diversos autores afirmam que a química das valvas dos ostracodes reflete as condições ambientais vigentes na água durante o período em que os mesmos viveram (ex. Chivas et al. 1983, De Deckker et al. 1988, Boomer 2002). Isto ocorre porque os íons que constituem a carapaça são retirados da água hospedeira. Mazzini (2005) realizou estudos do efeito vital com ostracodes modernos e observou pequenas variações isotópicas entre as carapaças e a água hospedeira, sugerindo que a calci- ficação não ocorre em equilíbrio, mas também não altera significativamente os resultados isotópicos.

Os estudos isotópicos em carapaças de ostracodes são ideais para assembleias de ambientes não-marinhos e marinhos profundos, porque a carapaça destes ostracodes apresentará composição química diferente da rocha matriz. Quando a rocha possui composição carbonática, possíveis processos secundários podem deixar a rocha e a carapaça carbonática com o mesmo valor isotópico. Os carbonatos de carapaças calcificam rapidamente e assim fornecem valores mais precisos do que aqueles valores obtidos em rochas carbonáticas.

Os valores das razões de $\delta^{13} \mathrm{C}$ e de $\delta^{18} \mathrm{O}$ permitem inferências de parâmetros como temperatura da água, salinidade, produtividade e disponibilidade de nutrientes, resultando em reconstruções paleoambientais, estratigrafia isotópica, detecção de períodos de anoxia, glaciações e muitos outros eventos que estão registrados de forma indireta nas carapaças dos ostracodes.

A base da geoquímica de isótopos estáveis teve início em 1947, quando Urey estudou as propriedades termodinâmicas dos carbonatos e sugeriu o uso da composição isotópica de oxigênio dos carbonatos como paleotermômetro. Seguiram-se os estudos de McCrea (1950), Epstein et al. (1951), Epstein \& Mayeda (1953) e Emiliani (1955), iniciando-se então o uso do valor da razão de $\delta^{18} \mathrm{O}$ para a elaboração de uma escala de carbonato biogênico em estudos de paleotemperatura. Desde os estudos de Emiliani (1955), a composição dos isótopos estáveis de foraminíferos é utilizada em estudos de paleotemperatura e em estudos de investigações dos ciclos glaciais-interglaciais do Quaternário. Os estudos em carbonato biogênico seguiram-se com Craig (1965), Stuiver (1968), Fritz \& Poplawski (1974) e Fritz et al. (1975).

Os primeiros estudos isotópicos em carapaças de ostracodes foram realizados por Allen et al. 1973 (in Durazzi 1977) utilizando alguns exemplares do Cretáceo. Durazzi (1977) divulgou os resultados de estudos sobre os isótopos estáveis em carapaças de ostracodes atuais, no qual concluiu que os valores das razões de $\delta^{18} \mathrm{O}$ apresentaram dados consistentes, mas não identificou correlação entre o valor da razão de $\delta^{13} \mathrm{C}$ e temperatura ou salinidade. As pesquisas em carapaças de ostracodes continuaram com Boersma \& Shackleton (1976), De Deckker et al. (1988) e Xia et al. (1997a, 1997b).

Recentemente, muitas análises de razões de $\delta^{13} \mathrm{C}$ e $\delta^{18} \mathrm{O}$ têm sido realizadas em carapaças 
de ostracodes atuais, terciários e quaternários marinhos (ex. Boomer et al. 2005, Janz \& Vennemann, 2005, Frenzel \& Boomer 2005, Bahr et al. 2006, Bornemann et al. 2007) e não-marinhos (ex. Holmes 1996, Boomer et al. 2000, Frogley et al. 2001, Mischke et al. 2002, Leng \& Marshall 2004, Anadón et al. 2006) e os resultados têm sido satisfatórios quando comparados com resultados obtidos em rocha total (carbonato) e em outros grupos de microfósseis.

Até o momento, poucos estudos foram conduzidos com ostracodes do Cretáceo e mais antigos. O Cretáceo foi um período de tempo onde o clima foi substancialmente mais quente que o atual, permitindo a deposição de plataformas carbonáticas e de sedimentos marinhos, os quais contêm os registros destes eventos e permitem muitas inferências paleoambientais (Crowley \& North 1991). Durante o Cretáceo ocorreram variações significativas no ciclo do carbono. A intensa captura de carbono orgânico causou uma mudança global da razão ${ }^{13} \mathrm{C} /{ }^{12} \mathrm{C}$ em carbonatos de mares profundos. A remoção do carbono orgânico enriqueceu os valores das razões de isótopos de carbono na água do mar pela concentração de ${ }^{13} \mathrm{C}$ (Scholle \& Arthur 1980, in Crowley \& North 1991) e, consequentemente, as razões isotópicas das carapaças calcárias que foram secretadas também enriqueceram.

As pesquisas com carapaças de ostracodes do Cretáceo têm sido mais aplicadas. Arp \& Mennerich (2008) analisaram os valores das razões de $\delta^{13} \mathrm{Ce} \delta^{18} \mathrm{O}$ em carapaças de ostracodes transicionais (zonas eulitorânea e sublitorânea rasa) e não-marinhos (supralitorâneos) do Cretáceo Inferior da Alemanha, compararam com abordagens sedimentológica e micropaleontológica e distinguiram variações eustáticas cíclicas. Estudos isotópicos de carbono e oxigênio realizados por Dias-Brito et al. (2001) em carófitas e em carapaças de ostracodes não-marinhos do Cretáceo médio, contribuíram para inferências evolutivas do Grupo Bauru, na Bacia do Paraná.

Dados obtidos com carapaças de ostracodes de idades mais antigas que o Cretáceo também têm apresentado resultados consistentes de isótopos estáveis. Schudack (1999) utilizou ostracodes marinhos e não-marinhos do Jurássico na reconstituição da história climática da Europa Central e da América do Norte e concluiu que os dados isotópicos obtidos nas carapaças foram preservados com fidelidade. Williams et al. (2006) realiza- ram análises isotópicas de carbono e oxigênio em carapaças de ostracodes de ambientes transicionais do Carbonífero da Escócia, os quais apresentaram mínima alteração diagenética, com resultados corroborando com os dados sedimentológicos e paleontológicos, permitindo sua aplicação fidedigna em reconstruções paleoambientais.

As dificuldades da realização de análises isotópicas em ostracodes do Cretáceo e mais antigos começam na desagregação da rocha bruta para permitir a recuperação das carapaças, pois a maioria destas amostras requer o uso de soluções químicas para desagregar, o que pode alterar o valor isotópico original preservado nas carapaças. Outro grande obstáculo é obter grande número de exemplares da mesma espécie em quantidade suficiente ( 2 a 10 valvas por amostra) ao longo do perfil de amostragem geológica, pois o valor isotópico entre diferentes táxons pode ser diferente devido ao efeito vital, o qual é desencadeado por fatores metabólicos durante a vida do ostracode (Schudack 1999, Grafenstein von et al. 1999, Simstich et al. 2004, Janz \& Vennemann 2005, Armstrong $\&$ Brasier 2005). Outro cuidado é na escolha de material isento de processos diagenéticos, evitando carapaças com traços de dissolução, deformadas e com recristalizações (Marshall 1992, Keatings et al. 2002, Mischke et al. 2008, Bennett et al. 2011). Sem processos secundários, as carapaças permitem a obtenção de valores de razões isotópicas mais precisos e mais genuínos.

Este texto apresenta sucintamente a metodologia para a análise isotópica de carbono e oxigênio em ostracodes do Cretáceo, suas aplicações na pesquisa paleoambiental e as principais dificuldades a serem superadas visando à obtenção de resultados satisfatórios, ou seja, aqueles preservados durante a sua formação.

\section{Isótopos estáveis}

Isótopos são átomos de um mesmo elemento químico, cujo núcleo contém o mesmo número de prótons (número atômico Z) com diferente número de nêutrons $(\mathrm{N})$ e, consequentemente, diferente massa atômica (A). As propriedades químicas dos isótopos são as mesmas, pois representam átomos de um mesmo elemento. No entanto, as propriedades físicas diferem (densidade, ponto de fusão, ligações com outros elementos), uma vez que dependem da massa do isótopo. Os isótopos estáveis se caracterizam por apresentarem confi- 
gurações nucleares estáveis, isto é, não alteram a massa ao longo da sua existência, ao contrário dos chamados instáveis ou radioativos, que decaem (mudam suas massas) por emissão de energia ou partículas subatômicas (Martinelli et al. 2009). Cada elemento tem um isótopo dominante "leve" $\left({ }^{12} \mathrm{C} \mathrm{e}{ }^{16} \mathrm{O}\right)$ e um ou mais isótopos "pesados" $\left({ }^{13} \mathrm{C}\right.$ e $\left.{ }^{18} \mathrm{O}\right)$, com abundância natural menor que $1 \%$ (Hoefs 2004).

\section{Fracionamento isotópico}

O fracionamento de isótopos estáveis corresponde ao processo de separação dos isótopos em duas substâncias ou duas fases da mesma substância com diferentes razões isotópicas, sendo causado por processos naturais ou artificiais.

Os principais fenômenos que produzem o fracionamento isotópico são: as reações de trocas de isótopos, os processos cinéticos, a difusão, outros fatores como pressão, composição química e estrutura cristalina (Hoefs 2004). Um exemplo é o fracionamento natural por trocas isotópicas entre isótopos de oxigênio presentes no vapor d'água de uma nuvem e nos pingos de chuva liberados pela nuvem. Outro exemplo é a fotossíntese, que pode fracionar o ${ }^{13} \mathrm{C}$. $\mathrm{O}$ efeito cinético está associado com processos de fracionamento incompletos e unidirecionais tipo evaporação, reação de dissociação, reação de causa biológica (como fotossíntese e processos bacterianos) e difusão. No processo de difusão os isótopos leves são mais móveis e, portanto, podem separar-se dos isótopos pesados. Desta forma, nos gases a molécula do isótopo leve vai difundir mais rapidamente, resultando num enriquecimento do sistema inicial em isótopo pesado.

Entretanto, a maioria dos processos de fracionamento isotópico surge a partir de efeitos de equilíbrio. Conforme White (2005), fracionamentos originados por efeitos de equilíbrio decorrem de movimentos rotacionais, translacionais e vibracionais das moléculas presentes em gases e líquidos e de átomos presentes em cristais, porque a energia associada a estes movimentos depende da massa. Os sistemas tendem a ajustar-se de modo a minimizar energia. Desta forma, os isótopos serão distribuídos de forma a minimizar a energia vibracional, rotacional e translacional de um sistema. Destes três tipos de energia, a vibracional é a mais importante e a que mais contribui para o fracionamento isotópico, além de ser o único modo

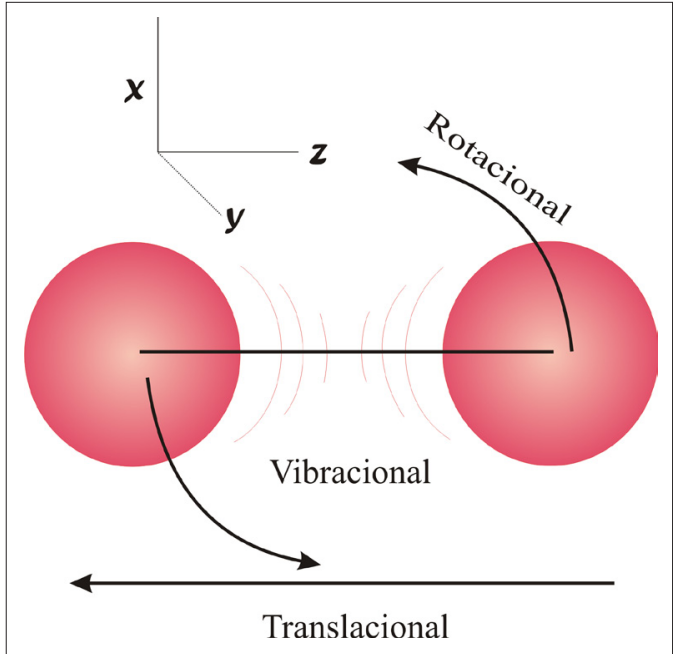

Figura 1. Os três modos de movimentos disponíveis para moléculas gasosas: vibracional, rotacional e translacional. Rotações podem ocorrer sobre os eixos y e $x$ (está ilustrado somente sobre o eixo y). Movimentos de translação são possíveis: nas direções x, y, e z (White, 2005).

de movimento disponível para átomos em sólidos. A Figura 1 demonstra os movimentos para uma molécula de dois átomos.

\section{Método analítico - espectrometria de massas}

A espectrometria de massas é a técnica analítica utilizada para identificar e quantificar moléculas e átomos de uma substância com base na massa dos isótopos. $\mathrm{O}$ espectrômetro que utiliza o sistema de entrada duplo é o espectrômetro de massas para razão isotópica (isotope ratio mass spectrometer) ou IRMS. Quando o espectrômetro está acoplado ao sistema de entrada utilizando um fluxo de gás hélio, passa a denominar-se IRMS de fluxo contínuo (continuos flow) ou CF-IRMS. Basicamente, um espectrômetro de massas pode ser dividido em quatro partes principais (Figura 2): o sistema de entrada, a fonte de íon, analisador de massas e o detector de íons (Hoefs 2004).

O sistema de entrada conduz a amostra de gás $\left(\mathrm{CO}_{2}\right)$ para a fonte de íon e pode ser duplo ou de fluxo contínuo. O sistema duplo possui uma válvula de comutação que permite uma análise rápida e consecutiva entre duas amostras de gases (amostra e material de referência) em poucos segundos. No sistema automatizado de fluxo contínuo existe um fluxo de gás de arraste (He ultra puro) que carrega o gás $\mathrm{CO}_{2}$ produzido até a entrada do espectrôme- 


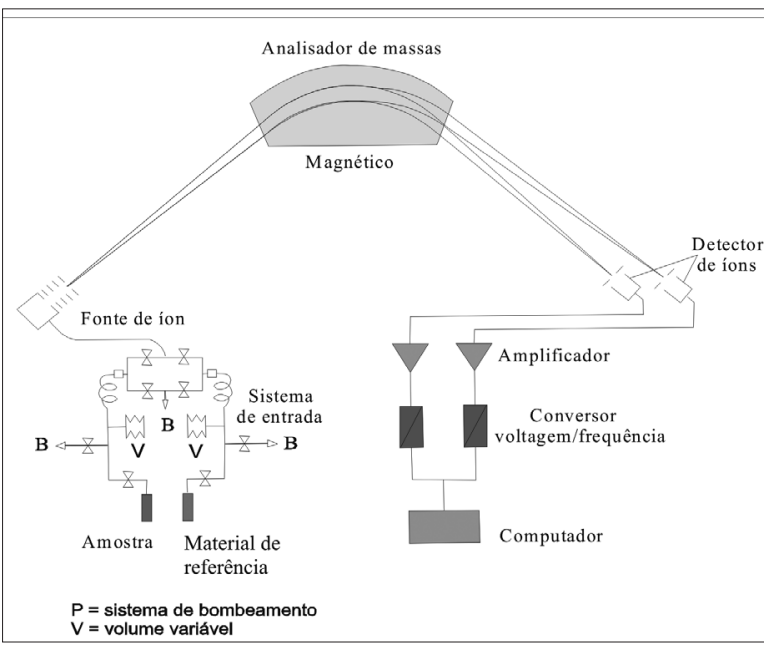

Figura 2. Esquema de um espectrômetro de massas, onde $\mathrm{B}$ refere-se ao sistema de bombeamento e $\mathrm{V}$ indica um volume variável (modificado de Hoefs, 2004).

tro. $\mathrm{Na}$ fonte de íons os gases são ionizados pela retirada de elétrons pelo filamento incandescente de tungstênio ou rênio. Após a ionização, a molécula pode ser fragmentada em diversos pedaços, produzindo um espectro de massa de um componente específico. Um campo magnético é usado para deixar os elétrons sobre uma trajetória espiral e posteriormente acelerá-los para dentro do analisador de massas, que separa a corrente de íon que surge da fonte de íon, conforme as massas. Após passar pelo campo magnético os íons separados são detectados por coletores de íons do tipo Faraday, os quais são posicionados ao longo do plano focal do espectrômetro de massas (Rollinson 1993, Hoefs 2004, Skoog et al. 2006). Os íons de massas 46/44 fornecem a razão ${ }^{18} \mathrm{O} /{ }^{16} \mathrm{O}$ e os íons de massas $45 / 44$ produzem a razão ${ }^{13} \mathrm{C} /{ }^{12} \mathrm{C}$ do $\mathrm{CO}_{2}$ (Figura 3 ).

O tratamento dos dados é feito computacionalmente com o processamento dos sinais, onde os feixes iônicos são coletados e amplificados. Cada análise da amostra inicia com um pico de centralização, seguido por picos de forma retangular do gás $\mathrm{CO}_{2}$ (material de referência) e posteriormente nove ou 10 picos sucessivos que são produzidos pela entrada seqüencial das amostras de $\mathrm{CO}_{2}$ puro no interior da fonte de íons (Spötl \& Vennemann 2003). As razões carga/massa obtidas são comparadas repetidas vezes a um material de referência para $\mathrm{CO}_{2}$. Quanto menor a massa da amostra, menor a intensidade dos pulsos elétricos registrados, e maior desvio padrão.

Para medir as razões dos $\delta^{13} \mathrm{C}$ e dos $\delta^{18} \mathrm{O}$ em valvas e carapaças de ostracodes, as mesmas são dissolvidas em ácido fosfórico $\left(\mathrm{H}_{3} \mathrm{PO}_{4}\right)$ em equipamentos automatizados de preparação do gás e acoplados aos espectrômetros, como o Gas Bench e o Kiel Device, liberando assim o $\mathrm{CO}_{2}$. Breitenbach \& Bernasconi (2011) realizaram comparações dos resultados obtidos para diferentes massas de carbonatos e concluíram que a massa de $20 \mu \mathrm{g}$ pode ser utilizada em equipamentos que utilizem o Gas Bench acoplado ao espectrômetro de fluxo contínuo.

\section{Notação e Padrões Internacionais}

Para a obtenção de um valor de isótopos estáveis é realizada a comparação relativa do valor da razão isotópica medida com o valor obtido em um material de referência ou padrão arbitrário. A unidade aceita para medidas de isótopos é o valor delta $(\delta)$, expresso em per mil (\%o). O valor $\delta$ é definido na Equação 1:

(Eq. 1) $\delta$ em $\%=\frac{\mathrm{R} \text { (amostra) }-\mathrm{R} \text { (referência) }}{\mathrm{R} \text { (referência) }} \times 1000$

Onde o $\mathrm{R}$ representa a razão isotópica medida do ${ }^{13} \mathrm{C} /{ }^{12} \mathrm{C}$ e do ${ }^{18} \mathrm{O} /{ }^{16} \mathrm{O}$ (razão do isótopo pesado para o isótopo leve). Essa razão é muito pequena e o resultado é multiplicado por mil (Hoefs 2004).

Se o valor de $\delta$ for maior que o zero ou positivo, a amostra está enriquecida no isótopo pesado (em relação ao material de referência utilizado). Se o valor $\delta$ for menor que o zero ou negativo, indica que a amostra está empobrecida no isótopo pesado (em relação ao material de referência utilizado). A Figura 4 apresenta o esquema da formação das

Figura 3. Diagrama apresentando a separação isotópica do $\mathrm{CO}_{2}$ liberado durante a espectrometria de massas (modificado de Patience e Kroon, 1994).

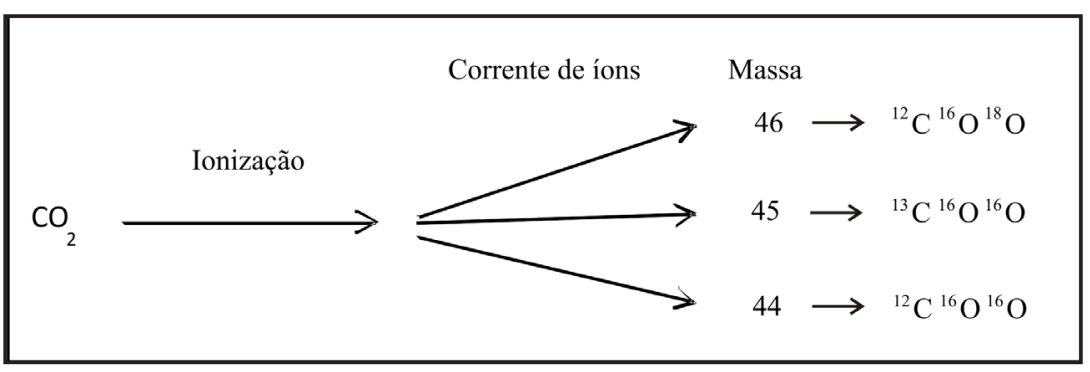




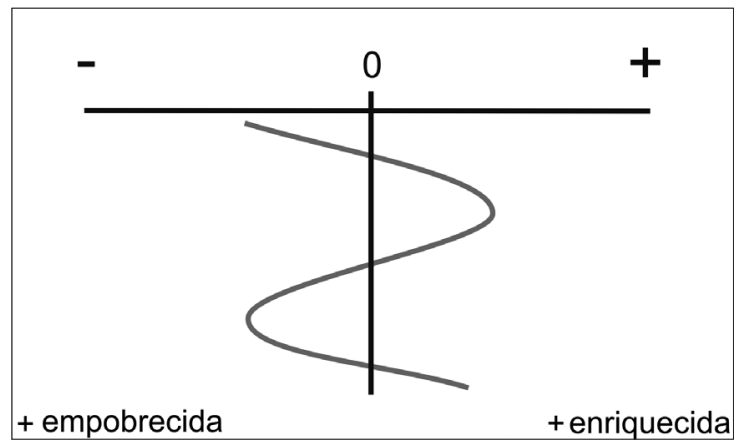

Figura 4. Esquema para geração da curva isotópica

curvas isotópicas em relação ao material de referência (zero).

Um material de referência ou padrão ideal usado mundialmente como o "ponto zero" sobre a escala $\delta$ precisa satisfazer os seguintes requisitos: ser homogêneo em composição; estar disponível em grandes quantidades; ser fácil de manusear para preparações químicas e medidas isotópicas e ter razão isotópica próxima da variação média na natureza. Em ostracodes, cuja constituição da carapaça é carbonato de cálcio $\left(\mathrm{CaCO}_{3}\right)$, são realizadas análises da razão $\delta^{13} \mathrm{C}$ (utilizando o material de referência conhecido como padrão $\mathrm{PDB}$ ) e da razão $\delta^{18} \mathrm{O}$ (utilizando como material de referência os padrões PDB e SMOW).

Padrão PDB: O padrão PDB original refere-se ao belemnite fóssil da Formação Pee Dee, do Cretáceo, localizada no Estado de Carolina do Sul, EUA. Este material de referência é utilizado em estudos de carbonatos de baixas temperaturas. Todas as outras análises da razão de $\delta^{18} \mathrm{O}$ (águas, silicatos, fosfatos, sulfatos e carbonatos de alta temperatura) são feitas em relação ao padrão SMOW (Hoefs 2004). Como o suprimento original deste material está esgotado, foram introduzidos padrões secundários cujas composições isotópicas são calibradas em relação ao PDB com o uso do gás $\mathrm{CO}_{2}$ comercial.

Atualmente são utilizados padrões V-PDB e V-SMOW (sintéticos e onde V significa Vienna). Os padrões comerciais são calibrados em relação ao PDB e os mais utilizados são o NBS-19 (dolomito) e o NBS-20 (calcário).

$\mathrm{Na}$ escala $\mathrm{PDB}$, os valores da razão $\delta^{18} \mathrm{O}$ de carbonatos marinhos estão próximos de zero, enquanto as amostras de carbonatos lacustrinos têm valores da razão $\delta^{18} \mathrm{O}$ negativos porque a água meteórica está empobrecida em ${ }^{18} \mathrm{O}$ em relação à água do mar (Faure \& Mensing 2005).

Padrão SMOW: O material de referência ou padrão SMOW (Standard Mean Ocean Water) era originalmente uma amostra de água hipotética com uma composição isotópica muito próxima da composição média da água do mar atual e não tratada, coletada próximo à linha do Equador. Atualmente, a amostra de água destilada distribuída como material de referência chama-se V-SMOW, à qual é muito próxima, mas não idêntica à composição isotópica do material de referência SMOW original. O V-SMOW serve como um material de referência para comparar razões de isótopos de hidrogênio e oxigênio, comuns na água do mar.

O processamento de dados das razões isotópicas apresenta os resultados para os $\delta^{18} \mathrm{O}$, tanto no padrão PDB quanto no padrão SMOW. Os resultados são apresentados graficamente gerando curvas em relação ao valor do material de referência (zero). Os resultados estão sempre relacionados ao isótopo pesado.

\section{Isótopos estáveis de carbono e seu fracionamento}

O carbono é um dos elementos mais abundantes na Terra. Possui número atômico 6 e massa atômica 12. Apresenta dois isótopos estáveis $\left({ }^{12} \mathrm{C}\right.$ e $\left.{ }^{13} \mathrm{C}\right)$ e quatro isótopos instáveis $\left({ }^{10} \mathrm{C},{ }^{11} \mathrm{C},{ }^{14} \mathrm{C}\right.$ e ${ }^{15} \mathrm{C}$ ). Os isótopos estáveis ocorrem nas seguintes proporções:

${ }^{12} \mathrm{C}$ : $98.89 \%$ (6 prótons e 6 nêutrons)

${ }^{13} \mathrm{C}$ : $\quad 1.11 \%$ (6 prótons e 7 nêutrons)

O carbono é essencial para a estruturação da vida, modula o clima do planeta e permite a oxigenação da atmosfera. O ciclo biogeoquímico realiza a transferência de carbono entre a atmosfera, a biosfera terrestre, a hidrosfera e a litosfera, o que ocorre em diferentes velocidades de transformação.

$\mathrm{O} \mathrm{CO}_{2}$ atmosférico se dissolve com facilidade na água, formando o ácido carbônico $\left(\mathrm{H}_{2} \mathrm{CO}_{3}\right)$. O ácido carbônico, por sua vez, ataca os silicatos constituintes das rochas produzindo íons bicarbonatos $\left(\mathrm{HCO}_{3}^{-}\right)$. Estes íons bicarbonatos dissolvidos na água de rios alcançam o mar, onde são assimilados pelos animais e formam sedimentos após a sua morte. O retorno do carbono à atmosfera ocorre por erupções vulcânicas, um processo de longa duração que depende dos mecanismos geológicos. Na superfície da Terra, o carbono é encontrado principalmente em reservatórios oxidados, como carbonatos sedimentares, $\mathrm{CO}_{2}$ (dióxido de carbono) e $\mathrm{HCO}_{3}^{-}$(íon bicarbonato); ou em reservatórios reduzidos, como matéria orgânica, combustível fóssil e C nativo (Armstrong \& Brasier 2005) 
Desta forma, os principais reservatórios terrestres de carbono são: a matéria orgânica, os carbonatos sedimentares e o manto da Terra. Estes reservatórios possuem características isotópicas distintas devido à ocorrência de dois tipos de reações de fracionamento (Hoefs 2004):

- As reações de trocas no equilíbrio isotópico dentro do sistema do carbono inorgânico $\left(\mathrm{CO}_{2}\right.$ atmosférico, bicarbonato dissolvido e carbonato sólido) levam a um enriquecimento do ${ }^{13} \mathrm{C}$ em carbonatos (formando reservatórios de carbonatos sedimentares, oxidados);

- Efeitos isotópicos cinéticos durante a fotossíntese concentram o isótopo leve ${ }^{12} \mathrm{C}$ no material orgânico sintetizado (formando reservatórios de matéria orgânica, reduzidos).

$\mathrm{O}$ fracionamento do carbono enriquece o carbono orgânico $\left({ }^{12} \mathrm{C}\right)$ e o carbono inorgânico $\left({ }^{13} \mathrm{C}\right)$. Em processos biológicos, quando o carbono inorgânico é usado para formar compostos orgânicos, $\mathrm{O}{ }^{12} \mathrm{C}$ reage mais rapidamente do que ${ }^{13} \mathrm{C}$, por ter a massa mais leve, e a matéria orgânica tende a se tornar enriquecida em ${ }^{12} \mathrm{C}$. Conforme Hoefs (2004) e Armstrong \& Brasier (2005), os carbonatos marinhos são isotopicamente pesados e apresentam um valor médio de razão de $\delta^{13} \mathrm{C}$ ao redor de $0 \%$ o (variável entre 1 e 3 \%o); enquanto a matéria orgânica é isotopicamente leve com um valor médio de razão de $\delta^{13} \mathrm{C}$ ao redor de $-25 \%$ (entre -19 e $-38 \%$ ). Conforme os autores citados, a matéria orgânica viva tem razão de $\delta^{13} \mathrm{C}$ fortemente negativo (entre -8 e $-30 \%$ o), porque os autotróficos utilizam o ${ }^{12} \mathrm{C}$ na fotossíntese. Os carbonatos não-marinhos possuem valores de razão de $\delta^{13} \mathrm{C}$ entre 1 e $-18 \%$ (Armstrong \& Brasier 2005) (Figura 5).

O fracionamento dos valores de $\delta^{13} \mathrm{C}$ entre o ar e a água é sensível às variações da temperatura (Wefer et al. 1999). Desta forma, baixas temperaturas resultam em grande fracionamento. Consequentemente, águas superficiais frias apresentam uma propensão para altos valores de $\delta^{13} \mathrm{C}$, exceto em áreas de misturas com águas profundas (regiões de ressurgência e de altas latitudes). A fotossíntese enriquece a superfície da água em ${ }^{13} \mathrm{C}$ quando comparada com águas subsuperficiais profundas e frias, pois utiliza $0{ }^{12} \mathrm{C}$ preferencialmente na formação da matéria orgânica. Os nutrientes que são estocados na zona fótica a partir da subsuperfície da água chegam junto com o excesso de ${ }^{12} \mathrm{C}$, o qual é liberado da matéria orgânica com os nutrientes, caindo dentro da termoclina (zona de variação brusca de temperatura que ocorre abaixo da camada superficial da água oceanos e lagos, situados em baixas e médias latitudes).

Os principais processos superficiais que explicam o fracionamento dos valores de $\delta^{13} \mathrm{C}$ em carbonatos marinhos e lacustres são: 1 ) a produtividade da água superficial, que remove o ${ }^{12} \mathrm{C}$ resultando em um valor de $\delta^{13} \mathrm{C}$ mais positivo; 2) a oxidação biológica devido à respiração da matéria orgânica dentro d'água e sobre o assoalho oceânico, resultando no retorno do ${ }^{12} \mathrm{C}$ para a coluna d'água e um valor da razão $\delta^{13} \mathrm{C}$ mais negativo; 3 ) a recirculação e mistura trazendo para a superfície o ${ }^{13} \mathrm{C}$; 4) os efeitos do micro habitat; 5) as jazidas de carbono formadas devido a elevação da produtividade primária, aumento de águas estagnadas e elevação das taxas de acumulação de sedimentos e que resultam no aumento do valor da razão $\delta^{13} \mathrm{C}$ no sistema oceano-atmosfera; 6) o efeito vital, que é a influência dos efeitos metabólicos de muitas espécies sobre a precipitação do carbonato; e 7) a diagênese, pois alguns fluidos diagenéticos tendem a capturar $\mathrm{O}^{12} \mathrm{C}$ e assim tornam o valor da razão $\delta^{13} \mathrm{C}$ suavemente mais negativa (Armstrong \& Brasier 2005).

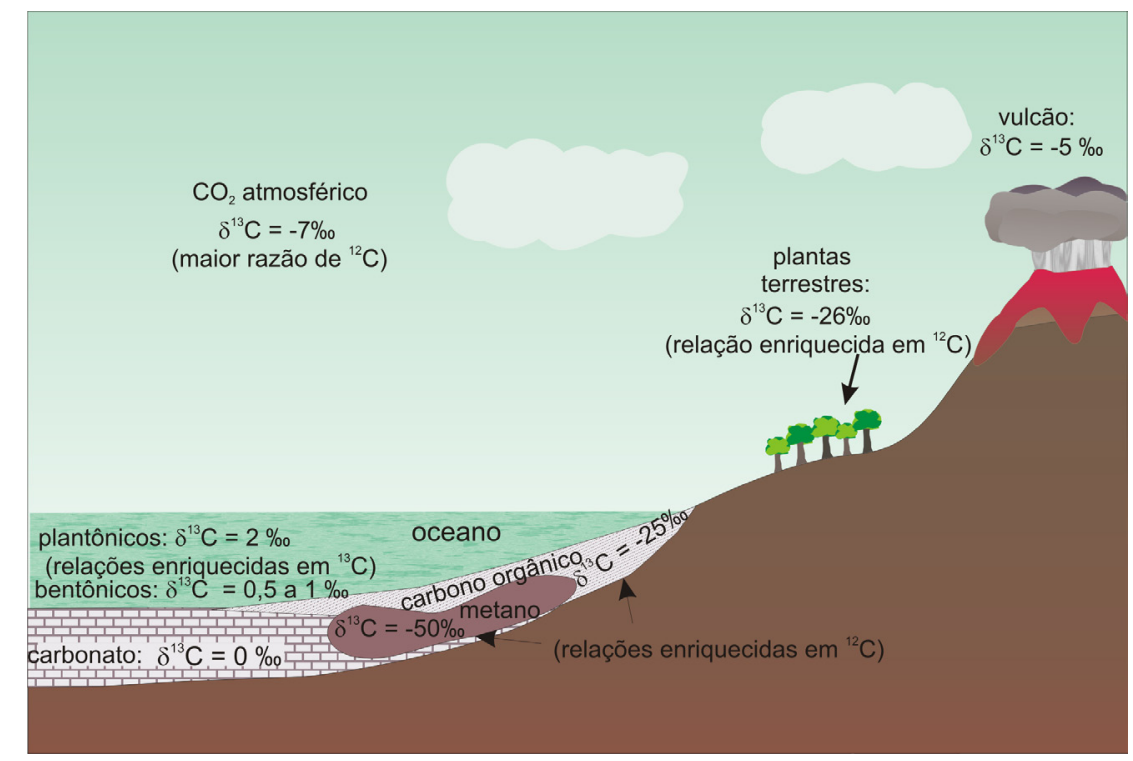

Figura 5. Valores médios de $\square^{13} \mathrm{C}$ na natureza. Valores em PDB. 


\section{Isótopos estáveis de carbono em sedimentos marinhos e suas carapaças carbonáticas}

Os valores das razões do $\delta^{13} \mathrm{C}$ em carbonatos marinhos e carapaças carbonáticas refletem uma combinação de produtividade oceânica, circulação do oceano e conteúdo relativo do carbono contido no carbonato, enquanto os valores das razões de $\delta^{13} \mathrm{C}$ na matéria orgânica refletem a produtividade no oceano, $\mathrm{o} \mathrm{CO}_{2}$ na superfície da água e a proveniência continental do material (Maslin \& Swann 2006).

Os carbonatos de ambientes marinhos terão valores da razão $\delta^{13} \mathrm{C}$ mais positivos (ricos em ${ }^{13} \mathrm{C}$ ) em períodos de alta produtividade orgânica e de temperaturas amenas. Nos episódios de transgressões marinhas e inundações de extensas plataformas carbonáticas, ocorrem as melhores condições de preservação da matéria orgânica (rica em ${ }^{12} \mathrm{C}$ ) retida em camadas ou lentes de folhelhos entre carbonatos. Desta forma, durante períodos de anoxia são depositados folhelhos de ambientes marinhos com valores da razão de $\delta^{13} \mathrm{C}$ mais negativos. Este empobrecimento se deve à alta concentração de ${ }^{12} \mathrm{C}$ no ambiente.

Os valores de $\delta^{13} \mathrm{C}$ em carapaças carbonáticas permitem rastrear a paleocirculação de águas profundas, o que é feito com a comparação de amostras de diferentes locais, com a mesma paleoprofundidade, reconstruindo o caminho percorrido pelas águas. Permitem também identificar eventos anóxicos e hipóxicos de águas de fundo.

\section{Isótopos estáveis de carbono em sedimentos lacustres e suas carapaças carbonáticas}

Análises de valores de razões de $\delta^{13} \mathrm{C}$ e $\delta^{18} \mathrm{O}$ em ostracodes são utilizadas em pesquisa paleolimnológica por constituírem os mais abundantes microfósseis carbonáticos nestes ambientes. A interpretação dos isótopos em ambientes aquáticos continentais é criteriosa, pois as variáveis que são medidas nos sedimentos orgânicos e inorgânicos são influenciadas por diversos processos ambientais interligados. Em geral, carbonatos, assim como ostracodes, possuem valores de isótopos relacionados à composição isotópica da água do lago no qual foram precipitados (Leng et al. 2006). Desta forma, a matéria orgânica encontrada em sedimentos de lagos pode fornecer informações importantes sobre o paleoambiente do lago. Os ostracodes compõem o carbonato autóctone de ambientes lacustres e as análises isotópicas de valores da razão de $\delta^{13} \mathrm{C}$ avaliam a paleoprodutividade do lago (Lister 1988).

\section{Isótopos estáveis de oxigênio e seu fracionamento}

O oxigênio é um elemento químico de símbolo $\mathrm{O}$, número atômico 8 e massa atômica 16 . Este elemento é o mais abundante sobre a Terra, atualmente representando cerca de $20 \%$ (por cento) da composição da atmosfera. O oxigênio ocorre em compostos gasosos, líquidos e sólidos, em sua maioria estáveis numa ampla escala de temperaturas, o que o torna um elemento muito interessante em geoquímica isotópica (Hoefs 2004), em estratigrafia isotópica de seções marinhas profundas e em inferências de paleotemperaturas.

O oxigênio possui três isótopos estáveis, com as seguintes abundâncias:

${ }^{16} \mathrm{O}: \quad 99.7630 \%$ (8 prótons e 8 nêutrons)

${ }^{17} \mathrm{O}: \quad 0.0375 \% \quad$ (8 prótons e 9 nêutrons)

${ }^{18} \mathrm{O}: \quad 0.1995 \% \quad$ (8 prótons e 10 nêutrons)

No ecossistema, o elemento oxigênio captado pelos seres vivos provém de três fontes principais: gás oxigênio $\left(\mathrm{O}_{2}\right)$, dióxido de carbono $\left(\mathrm{CO}_{2}\right)$ e água $\left(\mathrm{H}_{2} \mathrm{O}\right)$. $\mathrm{O}$ valor da razão $\delta^{18} \mathrm{O}$ apresenta diversas possibilidades de fracionamento, como as reações de troca de equilíbrio; os processos cinéticos como fotossíntese e a respiração; $\mathrm{e}$ as diferenças de pressão de vapor. A mais atuante é a que ocorre entre a água líquida e o vapor de água. Devido à grande abundância e a elevada diferença de massas, a razão ${ }^{18} \mathrm{O} /{ }^{16} \mathrm{O}$ é a normalmente determinada, podendo variar em cerca de $10 \%$ (por mil). As águas meteóricas (incluindo vapor, chuva, nuvem) apresentam uma ampla variação, com valores entre - 40 e $10 \%$ o, enquanto as águas oceânicas possuem valor de $\delta^{18} \mathrm{O}$ em torno de $0 \%$ (variável entre 0 e $2 \%$ ) (Hoefs 2004).

Quando a água do mar evapora ocorre um processo de fracionamento natural e mais moléculas de água com ${ }^{16} \mathrm{O}$ são evaporadas (por serem leves), enriquecendo a água atmosférica, nuvens e chuvas com o ${ }^{16} \mathrm{O}$. Em um ambiente não glacial o balanço de ${ }^{18} \mathrm{O}$ para ${ }^{16} \mathrm{O}$ é mantido porque a água da chuva caindo sobre o continente, rapidamente retorna para os oceanos pelos rios (Figura 6).

Em contraste, durante o período glacial o balanço de ${ }^{18} \mathrm{O}$ para ${ }^{16} \mathrm{O}$ é o contrário porque a mistura atmosférica não retorna rapidamente para o oceano, mas cai como neve e é estocada nas calotas de gelo. Como conseqüência, durante o período glacial o oceano é enriquecido em ${ }^{18} \mathrm{O}$. As nuvens tendem 


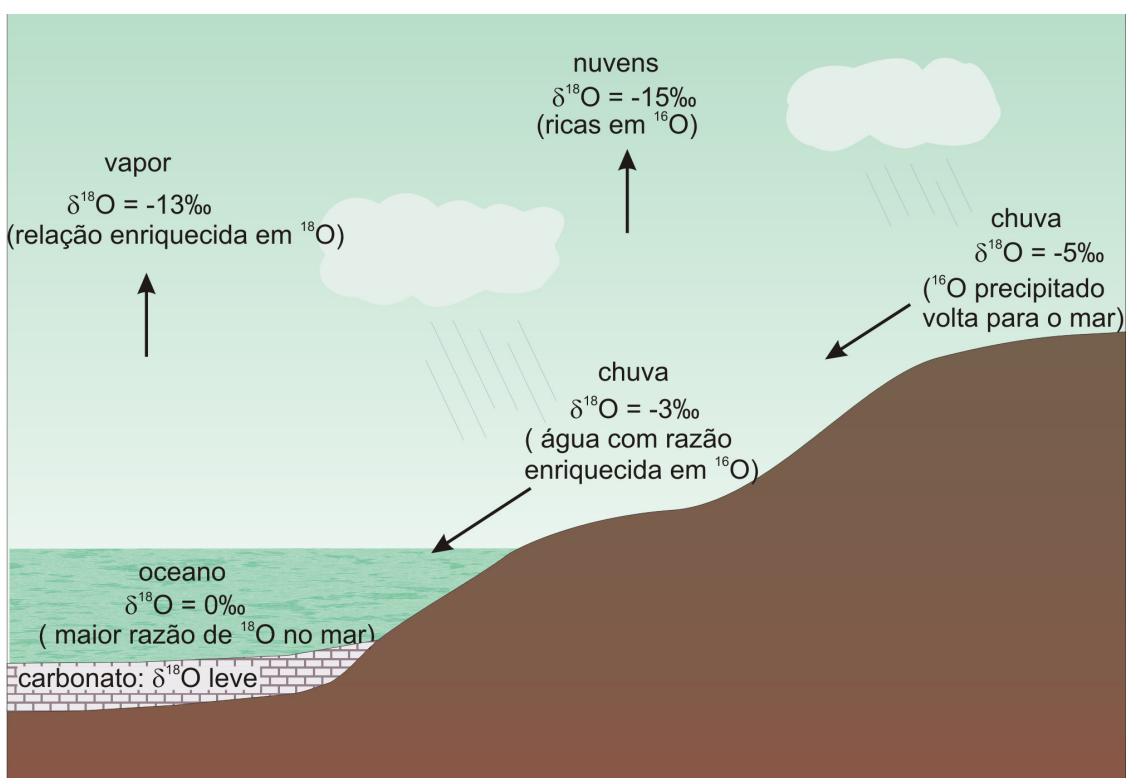

Figura 6 . Fracionamento do $\square^{18} 0$ durante um período não glacial. 0 carbonato formado neste período será isotopicamente leve, isto é, enriquecido em ${ }^{16} \mathrm{O}$. Isto ocorre porque $0{ }^{16} \mathrm{O}$ evaporado volta para a água do mar pelas chuvas e pelos rios mantendo o equilíbrio entre os dois isótopos. Valores em PDB.

a evaporar em baixas latitudes e moverem-se em direção aos pólos, onde o $\mathrm{H}_{2}{ }^{16} \mathrm{O}$ é estocado nas calotas polares (Figura 7).

O Cretáceo foi um período reconhecidamente quente, onde não havia calotas de gelo. Assim, os valores de razão $\delta^{18} \mathrm{O}$ obtidos em carapaças de ostracodes deverão indicar variações de temperaturas entre águas quentes e amenas. Para Maslin \& Swann (2006), os valores de razão $\delta^{18} \mathrm{O}$ sugerem que as águas de fundo dos oceanos do Cretáceo apresentavam temperaturas entre 10 e $15^{\circ} \mathrm{C}$, radicalmente diferente dos dias atuais $\left(4 \mathrm{e}-1{ }^{\circ} \mathrm{C}\right)$.

$\mathrm{O}$ conteúdo de sal na água também afeta o fracionamento isotópico. Existe uma excelente correlação entre estimativas de paleotemperatura da água e estimativas da salinidade em cada bacia oceânica, sendo que altas salinidades estão relacionadas com altas temperaturas, e vice-versa. Isto ocorre porque altas temperaturas favorecem a evaporação, enquanto o vapor da atmosfera condensa em regiões frias (Wefer et al. 1999).

Os principais processos superficiais que fracionam os isótopos estáveis de ${ }^{16} \mathrm{O}$ e ${ }^{18} \mathrm{O}$ em carapaças de carbonatos, segundo Armstrong \& Brasier (2005), são: 1) a composição isotópica da água, pois evapora mais ${ }^{16} \mathrm{O}$ do que ${ }^{18} \mathrm{O}$ na água dos oceanos, e precipita mais ${ }^{16} \mathrm{O}$ do que ${ }^{18} \mathrm{O}$ pelas nuvens de chuva; 2) a temperatura, pois os carbonatos precipitados em água morna incorporam mais ${ }^{16} \mathrm{O}$ e menos
${ }^{18} \mathrm{O}$ (e frequentemente tem um valor de razão $\delta^{18} \mathrm{O}$ mais negativo) que aqueles precipitados em águas frias. Ocorre um fracionamento de cerca de $0.22 \%$ PDB por $\left.1^{\circ} \mathrm{C} ; 3\right)$ a fase mineral, pois a calcita magnesiana é enriquecida em ${ }^{18} \mathrm{O}$ quando comparada com a calcita; 4) o efeito vital decorrente da influência dos efeitos metabólicos de muitas espécies sobre a precipitação do carbonato; e 5) a diagênese, pois a maioria dos fluidos diagenéticos tende a capturar $\mathrm{O}^{16} \mathrm{O}$ e assim tornar a razão $\delta^{18} \mathrm{O}$ mais negativa.

\section{Isótopos estáveis de oxigênio em sedimentos marinhos e suas carapaças carbonáticas}

Os valores da razão $\delta^{18} \mathrm{O}$ dos oceanos são afetados principalmente pela temperatura e pela composição isotópica da água. Assim, respondem às flutuações de temperatura global do planeta, que em última instância determinam o volume de gelo nos pólos, e podem ser considerados rastreadores de glaciações ou períodos de tempos frios.

Os carbonatos precipitados na água do mar durante períodos glaciais têm o valor da razão $\delta^{18} \mathrm{O}$ mais positivo do que aqueles encontrados na época de baixos volumes de gelo. Os carbonatos precipitados em águas hipersalinas geralmente têm como resultado um valor da razão $\delta^{18} \mathrm{O}$ mais negativa. Além da temperatura e da composição isotópica da água do mar, fatores como a concentração do íon carbonato, a atividade fotossintética de algas simbiontes e o $\mathrm{pH}$ da água também podem alterar a composição do valor da razão $\delta^{18} \mathrm{O}$ de carapaças (Hoefs 2004).

\section{Isótopos estáveis de oxigênio em sedimentos lacustres e suas carapaças carbonáticas}

Os ostracodes são os microfósseis carbonáticos predominantes em ambientes lacustres. Os carbonatos depositados em água doce apresentam uma ampla variação na composição isotópica, 
dependendo, sobretudo, da composição isotópica da água da chuva na área da bacia hidrográfica, sua quantidade e sazonalidade, da temperatura, da taxa de evaporação, da umidade relativa e da produtividade biológica. Os carbonatos depositados em água doce tendem a incorporar mais ${ }^{16} \mathrm{O}$ e menos ${ }^{18} \mathrm{O}$ que aqueles precipitados na água do mar normal. Os carbonatos lacustres consistem de componentes detritais, precipitados autigênicos, organismos neríticos e bentônicos. Para uma análise completa da coluna d'água deve-se analisar os materiais separadamente, optando por espécies com história de vida sazonal conhecida. (Hoefs 2004).

As carapaças de ostracodes possuem fracionamentos diferentes em diferentes microhabitats ou entre diferentes espécies. As análises dos valores da razão $\delta^{18} \mathrm{O}$ avaliam a paleotemperatura do lago. Algumas espécies bentônicas preferem os ambientes rasos e mornos, outras os frios e profundos, e este fator influenciará fortemente o resultado do sinal isotópico (Lister 1988).

\section{Técnicas de preparação da amostra}

O tratamento a ser dispensado à rocha para possibilitar sua desagregação e a recuperação de ostracodes depende da composição da rocha e de suas porosidade e permeabilidade. A desagregação de rochas carbonáticas tem obtido bons resultados com o uso de ácido acético glacial (Bourdon 1962, Lethiers \& Crasquin-Soleau 1988, Moura et al. 1996, Lirer 2000), com controle do tempo de reação para não dissolver as carapaças (Rodrigues et al. 2012). As rochas sedimentares que possuem matéria orgânica na sua composição são desagregadas para a recuperação de ostracodes com o uso de peróxido de hidrogênio (Grekoff 1956, Sohn 1961).

Em 1966 Emiliani já postulava que diferentes técnicas de desagregação e remoção da matéria orgânica antes da análise isotópica podem alterar os resultados isotópicos. O uso de soluções para a desagregação da rocha pode dissolver ou erodir a camada superficial da carapaça apresentando resultados isotópicos distorcidos ou até mesmo reagir com a mesma e alterar os valores isotópicos originais.

Durazzi (1977) realizou estudos preliminares da razão de $\delta^{18} \mathrm{O}$ e $\delta^{13} \mathrm{C}$ utilizando carapaças imersas no hipoclorito de sódio (5\%) em diferentes tempos (para remoção da matéria orgânica dos ostracodes recentes), concluindo que o tempo de exposição tem pequeno efeito sobre as composições isotópicas.
Keatings et al. (2006) testaram vários métodos de pré-tratamento de valvas de ostracodes quaternários e recentes, incluindo a imersão em reagentes como peróxido de hidrogênio e hipoclorito de sódio. Os testes apresentaram pequeno efeito sobre os resultados dos valores das razões $\delta^{13} \mathrm{Ce} \delta^{18} \mathrm{O}$ na maioria das valvas. Os autores consideraram o uso do método de peróxido de hidrogênio como bom para proceder às análises de isótopos de oxigênio, por não apresentar alterações entre as valvas dos ostracodes não-marinhos, tratadas e não-tratadas. Li et al. (2007) realizaram testes com valvas de ostracodes lacustres subfósseis, com a aplicação de diferentes métodos de pré-tratamento da amostra (sem tratamento, com metanol, com água desionizada e metanol, e com peróxido de hidrogênio), e analisaram valvas de diferentes tamanhos de duas espécies distintas de ostracodes, concluindo que os diferentes pré-tratamentos não resultaram em efeitos significativos sobre os valores de isótopos estáveis de carbono e oxigênio, com apenas uma diminuição sutil dos valores das razões $\delta^{13} \mathrm{C}$ após a remoção da matéria orgânica.

Rodrigues et al. (2012) realizaram diversos ensaios físicos, químicos e físico-químicos para a desagregação de rochas carbonáticas do Cretáceo com recuperação de ostracodes. Os melhores resultados, com carapaças limpas e sem indícios de dissolução, indicaram o uso de ácido acético na sua forma mais pura, à temperatura ambiente e com tempo de reação controlado. Estudos realizados por Rodrigues et al. (em preparação) comparam valores das razões $\delta^{13} \mathrm{C}$ e $\delta^{18} \mathrm{O}$ de carapaças de ostracodes com valores das razões $\delta^{13} \mathrm{C}$ e $\delta^{18} \mathrm{O}$ obtidos em rocha total e em carapaças de ostracodes recuperadas manualmente na rocha, e os resultados obtidos habilitaram a utilização do ácido acético durante o pré-tratamento da amostra.

Os espécimes selecionados para as análises isotópicas precisam receber limpeza para excluir qualquer possibilidade de incrustações de material sedimentar e matéria orgânica. Inicialmente os ostracodes podem ser limpos com o pincel e água desionizada ultra pura para remover as partículas visíveis (Jin et al. 2006). Caso isto não seja suficiente, pode-se utilizar ultrassom contendo água desionizada.

O procedimento padrão para a preparação dos carbonatos para as análises isotópicas de carbono e de oxigênio é a reação com ácido fosfórico 100 \% a $25^{\circ} \mathrm{C}$, conforme proposto por McCrea em 1950. O método de aplicação do ácido fosfórico varia 
entre os laboratórios. Em equipamento acoplado ao espectrômetro de massas, o ácido fosfórico a 100 \% é adicionado à amostra de ostracode, reagindo em temperaturas entre 20 e $90^{\circ} \mathrm{C}$, liberando o $\mathrm{CO}_{2}$ (Hoefs 2004).

\section{Desafios da aplicação de isótopos estáveis em carapaças de ostracodes}

A aplicação da análise isotópica em ostracodes do Cretáceo deve incluir alguns cuidados durante a obtenção das valvas e carapaças, com o intuito de preservar os valores isotópicos originais das mesmas.

Quanto mais coesa estiver a rocha mais difícil será o processo de recuperação de valvas e carapaças, sendo necessário o uso de diferentes reagentes químicos. As soluções químicas como o peróxido de hidrogênio (Keatings et al. 2006, Li et al. 2007, Serrano et al. 2008) e o ácido acético (Rodrigues et al. 2012), a água utilizada na lavagem com peneiras (Mischke et al. 2008) e até mesmo a temperatura da chapa quente e da estufa (Sperling et al. 2002) podem alterar os valores isotópicos originais dos ostracodes. Li et al. (2007) sugerem que a etapa de desagregação química não seja realizada para a análise de valores das razões $\delta^{13} \mathrm{C}$ e $\delta^{18} \mathrm{O}$, o que evitaria o desperdício e a contaminação das amostras alterando o valor isotópico. Mischke et al. (2008) avaliaram as carapaças de ostracodes que foram peneiradas com o uso de água e de álcool, e as análises isotópicas das amostras preparadas com água apresentaram valores alterados. Quanto mais antigo o material, menor poderá ser a quantidade de ostracodes que estarão preservados, o que dificulta a amostragem para as análises isotópicas e impossibilita estudos adicionais.

Para iniciar a desagregação da rocha bruta utiliza-se uma prensa mecânica para a obtenção de fragmentos menores e passíveis de quebra manual, a qual pode ser realizada sob a lupa binocular com auxílio de alicate pequeno, agulhas, pincéis e água desionizada ultra pura. O material desagregado manualmente deve ser triado, permitindo a recuperação de ostracodes, os quais algumas vezes ainda estarão parcialmente imersos nos fragmentos de rocha. $\mathrm{O}$ material aderido à superfície das valvas e carapaças deve ser removido manualmente com a utilização de pincel fino e agulha, sob lupa binocular. Quando necessário coloca-se o ostracode em lâmina reservatório, devidamente fechada e adicionada de água desionizada ultra pura, a qual é colocada na lavadora de ultrassom contendo igualmente água desionizada, onde o tempo necessário para limpeza de valvas ou carapaças é variável e deve ser monitorado para evitar quebras e perda de material.

As amostras selecionadas devem ser compostas preferencialmente por valvas limpas, sendo necessários 40 a $200 \mu \mathrm{g}$, dependendo da precisão analítica do espectrômetro de massas que vai ser utilizado, o que pode corresponder de 2 a 10 valvas para a realização de cada análise.

Utilizar uma única espécie é prudente para evitar distorções decorrentes do efeito vital (influência dos efeitos metabólicos de muitas espécies sobre a precipitação do carbonato) que existe entre táxons num mesmo habitat. Holser et al. (1996) sugerem amostragens a nível de espécies ou gêneros e argumentam que as distorções decorrentes do efeito vital são sutis e geralmente não alteram a forma da curva. Schudack (1999) analisou isótopos de ostracodes jurássicos e sugeriu alguns cuidados na escolha dos espécimes, como selecionar exemplares que apresentam boa preservação das estruturas das carapaças e preferencialmente de amostras mono-específicas, as quais apresentam efeito vital semelhante gerando um mesmo padrão de tendência. Alguns pesquisadores simularam e calcularam o valor do efeito vital de ostracodes do Mioceno a atuais (Grafenstein von et al. 1999, Simstich et al. 2004, Janz \& Vennemann 2005), considerando como efeito vital o valor do desvio padrão obtido entre espécies num mesmo ponto amostral. Muitas vezes será possível realizar a análise isotópica somente em diferentes gêneros de ostracodes. A distribuição de diversas espécies ou gêneros de ostracodes num único gráfico permite a integração dos resultados e a formação de uma curva de tendência geral da variação dos valores isotópicos (Tütken et al. 2006, Arp \& Mennerich 2008).

Para a realização de análises isotópicas é importante também que os espécimes estejam bem preservados e livres de alterações diagenéticas (Marshall 1992, Holser et al. 1996, Armstrong \& Brasier 2005, Bennett et al. 2011). No entanto, no estudo de ostracodes do Cretáceo, muitas vezes as carapaças estão bem fechadas, preenchidas com cimento, o que pode alterar o valor isotópico, devendo-se optar por valvas, quando possível. A diagênese pode afetar o sinal do valor da razão $\delta^{18} \mathrm{O}$ por cimentação, recristalização e dissolução, tornando-o isotopicamente menor que o valor original; o valor de $\delta^{13} \mathrm{C}$ 
é alterado com menos facilidade (Marshall 1992). A dolomitização de calcários pode resultar em problemas na interpretação dos dados isotópicos (Hoefs 2004). Os efeitos da diagênese precoce sobre os valores de isótopos estáveis foram pesquisados em microscópio por Keatings et al. (2002), utilizando valvas inalteradas e extremamente alteradas de ostracodes do Quaternário, e os resultados sugeriram que os efeitos da diagênese sobre o resultado das análises isotópicas foram mínimos. Mischke et al. (2008) avaliaram as recristalizações superficiais das carapaças de ostracodes utilizando imagens de MEV (Microscopia Eletrônica de varredura) e difração de raios X. Bennett et al. (2011) compararam carapaças de ostracodes do Carbonífero com as de ostracodes recentes, e identificaram seis estágios diagenéticos com o uso de imagens de MEV, de análises de cimentos diagenéticos e recristalizações sob microscópio de luz polarizada, de MEV e catodoluminescência e de análises geoquímicas em microssonda eletrônica.

Ishimura et al. (2004) desenvolveram um sistema analítico de fluxo contínuo que requer somente $0,2 \mu \mathrm{g}$ de $\mathrm{CaCO}_{3}$ para as análises de valores das razões $\delta^{13} \mathrm{C}$ e $\delta^{18} \mathrm{O}$. Sakai (2006) adaptou equipamentos e conseguiu amostrar fragmentos de testas de foraminíferos do Pleistoceno por micropulverizações diretamente no espécime contido em uma fina lâmina de rocha, procedendo à análise isotópica para carbono e oxigênio. Desta forma o autor obteve amostras sem necessidade de uso de reagentes químicos e livres de processos diagenéticos, evitando que o sinal isotópico fosse alterado. Para ostracodes esta técnica apresenta a limitação da identificação de espécies e até mesmo gêneros, diretamente em lâminas delgadas, nos mais variados cortes. Sakai \& Kodan (2011) realizaram micropulverização de amostras de carbonatos e rapidamente recuperaram de 5 a $10 \mu \mathrm{g}$, com taxa de recuperação do pó de carbonato superior a 90 \%. Com o aperfeiçoamento dos espectrômetros de massa e da técnica de micropulverização e coleta de amostra, a quantidade requerida para a análise isotópica será cada vez menor e isto permitirá o aumento da resolução analítica. Uma carapaça fechada e contendo cimento interno poderá ser amostrada pontualmente.

Considerando-se as particularidades da aplicação de isótopos estáveis em ostracodes do Cretáceo, é cautelar interpretar os resultados pela forma e pela variação das curvas isotópicas, ou seja, pela tendência geral obtida e não pelo valor numérico de cada amostra em cada ponto da curva. Desta forma, a reconstrução paleoambiental de seções marinhas e lacustres apresentará resultados menos tendenciosos e com valores mais próximos das condições vigentes à época de sua formação.

\section{Aplicações na reconstrução paleoambiental}

As carapaças de ostracodes fornecem razões de valores das razões $\delta^{13} \mathrm{C}$ e $\delta^{18} \mathrm{O}$ que registram a composição da água em que eles se desenvolveram. Estes sinais podem ser usados na reconstrução de mudanças paleoambientais (Armstrong \& Brasier 2005). Os valores das razões $\delta^{13} \mathrm{C}$ e de $\delta^{18} \mathrm{O}$ são os indicadores medidos para as reconstruções paleoambientais (as variáveis proxies). Eles podem ser esperados, mas não podem ser observados e são utilizados para a obtenção de parâmetros como: temperatura, salinidade, disponibilidade de nutrientes e produtividade (Wefer et al. 1999).

A reconstrução paleoambiental é muito importante para a compreensão dos climas atuais e da circulação geral dos oceanos, possibilitando contribuir para a construção de modelos que podem ser usados na caracterização de rochas geradoras e rochas-reservatório, visando à obtenção de recursos energéticos, como por exemplo, o petróleo. Os estudos dos paleoambientes de lagos permitem a elucidação de eventos paleoclimáticos regionais que podem contribuir para a elucidação de eventos globais.

As variações na concentração e na composição química e isotópica da matéria orgânica e dos carbonatos irão ocorrer quando houver modificações nas características químicas, físicas e biológicas da massa d'água oceânica. Estas variações podem refletir eventos paleoceanográficos que afetaram os oceanos numa determinada fração do tempo geológico (são eventos globais), podendo constituir excelentes marcos de correlação cronoestratigráfica (Rodrigues 1995, Holser et al. 1996). Como eventos globais no registro geológico podem ser considerados: os eventos anóxicos (com análises dos valores da razão $\delta^{13} \mathrm{C}$ ) e os eventos glaciais (com análises dos valores da razão $\delta^{18} \mathrm{O}$ ).

A anoxia é produzida quando a demanda do oxigênio é superior ao suprimento, resultando na deficiência severa de mesmo. O consumo do oxigênio na coluna d'água é um processo bioquímico resultante da degradação da matéria orgânica por bactérias aeróbicas. Desta forma, o aumento da produtividade orgânica primária ocasionará o 
aumento da demanda de oxigênio, aumentando assim a zona de mínimo oxigênio. $\mathrm{Na}$ coluna d'água, a zona de mínimo oxigênio será no setor onde não ocorre circulação da água. A ocorrência de anoxia na interface água-sedimento possibilita a preservação da matéria orgânica autóctona (fito e zooplâncton) que atinge o fundo pela ausência de degradação aeróbica, que é o processo mais efetivo de destruição da matéria orgânica, tanto na coluna d'água quanto no trato digestivo de organismos bentônicos (Rodrigues 1995).

Os eventos anóxicos oceânicos são estabelecidos quando as condições oceânicas globais propiciam a deposição de sedimentos com altas concentrações de ${ }^{12} \mathrm{C}$, relacionados às incursões marinhas (superfície de máxima inundação) e episódios de extinções. Os mais importantes eventos anóxicos conhecidos ocorreram no Cretáceo, nos limites Aptiano-Albiano e Cenomaniano-Turoniano, com extensas deposições de folhelhos pretos e margas escuros, potenciais geradoras de hidrocarbonetos.

A presença de condições ambientais anóxicas pode ser detectada nas sequências sedimentares pelos seguintes dados: aumento da concentração de matéria orgânica rica em hidrogênio (predominando o ${ }^{12} \mathrm{C}$ ) e aumento dos valores da razão $\delta^{13} \mathrm{C}$ dos carbonatos, devido ao enriquecimento de $\mathrm{CO}_{2}$ dissolvido na água em ${ }^{13} \mathrm{C}$ (Rodrigues 1995). Este enriquecimento pode ser ocasionado pelo aumento de organismos fotossintéticos, que retiram preferencialmente ${ }^{12} \mathrm{C}$ durante a fotossíntese, e pelo menor retorno de $\mathrm{CO}_{2}$ rico em ${ }^{12} \mathrm{C}$ derivado da oxidação da matéria orgânica em condições aeróbicas, em função da preservação de uma grande parte desta matéria orgânica durante o evento anóxico (Armstrong \& Brasier 2005).

Os eventos glaciais podem significar o rebaixamento do nível do mar e a deposição de turbiditos, que podem resultar em reservatórios de hidrocarbonetos em águas profundas, entre outros tipos de depósitos. É possível reconstituir a evolução da massa d'água oceânica durante o tempo geológico, analisando as diferentes concentrações de valores da razão $\delta^{18} \mathrm{O}$ nos carbonatos ou nas carapaças carbonáticas de microfósseis. Isto ocorre porque na evaporação, o vapor d'água é enriquecido em ${ }^{16} \mathrm{O}$ quando comparado com a água onde se originou. Assim, nas glaciações, os oceanos ficam enriquecidos em ${ }^{18} \mathrm{O}$, devido a maior retenção de água da chuva no gelo. Durante a deposição dos carbonatos o aumento da temperatura privilegia a deposição de carbonatos mais ricos em ${ }^{16} \mathrm{O}$, enquanto a dimi- nuição da temperatura induz a um efeito inverso, formando carbonatos mais ricos em ${ }^{18} \mathrm{O}$. Considerando que o Cretáceo foi um período uniformemente quente e sem a ocorrência de calotas de gelo, os valores da razão $\delta^{18} \mathrm{O}$ obtidos nas carapaças de ostracodes indicarão a variação entre temperaturas quentes e amenas.

\section{Agradecimentos}

Os autores agradecem a Ana Maria Mizusaki (UFRGS), Alcides Nóbrega Sial (UFPE), Roberto Ventura (UnB), Luis Mancini (UnB), Egberto Pereira (UERJ), Nelson Marques (UERJ), Cristianini T. Bergue (Unisinos), Candido Moura (UFPA) e a todos que contribuíram para o entendimento da técnica analítica de espectrometria de massas e da aplicação da análise de isótopos estáveis em ostracodes.

\section{Referências}

Anadón P., Moscariello A., Rodríguez-Lázaro J., Filippi M.L. 2006. Holocene environmental changes of Lake Geneva (Lac Le'man) from stable isotopes $\left(\mathrm{d}^{13} \mathrm{C}, \mathrm{d}^{18} \mathrm{O}\right)$ and trace element records of ostracod and gastropod carbonates. Journal of $\mathrm{Pa}$ leolimnology 35:593-616.

Armstrong, H.A., Brasier, M.D. 2005. Microfossil, stable isotopes and ocean-atmosphere history. In: Microfossils. Blackwell Publishing-Malden-USA. 2 ed. 4:25-34.

Arp G., Mennerich C. 2008. Ostracodes assemblages, palaeoenvironment ans cyclicity of Purbeck-type sediments of the Münder Formaton (Lower Cretaceous, Hils Syncline, N-Germany). Palaeogeography, Palaeoclimatolgy, Palaeoecology 264:230-249.

Bahr A., Arz H.W., Lamy F., Wefer G. 2006. Late glacial to Holocene paleoenvironmental evolution of the Black Sea, reconstructed with stable oxygen isotope records obtained on ostracod shells. Earth and Planetary Science Letters 241:863-875.

Bennett C.E., Williams M., Leng M.J., Siveter D.J., Davies S.J., Sloane H.J., Wilkinson I.P. 2011. Diagenesis of fossil ostracods: Implications for stable isotope based palaeoenvironmental reconstruction. Palaeogeography, Palaeoclimatology, Palaeoecology 305(1-4):150-161.

Bergue C.T. 2006. A aplicação dos ostracodes (Crustacea) em pesquisas paleoceanográficas e paleoclimáticas. Terre Didatica 2(1):54-66.

Boersma A., Shackleton N.J. 1976. Paleogene isotopic paleoceanographic. Abstracts. Geological Society of America 8:784-785.

Boomer I. 2002. Environmental Applications of Ma- 
rine and Fresswater Ostracoda. In: Haslett S.K. (edit.). Quaternary Environmental Micropalaeontology. Oxford University Press Inc., New York. p. 115-138.

Boomer I., Aladin N., Plotnikov I., Whatley R. 2000. The palaeolimnology of the Aral Sea: a review. Quaternary Science Reviews 19:1259-1278.

Boomer I., Grafenstein von U., Guichard F. Bieda S. 2005. Modern and Holocene sublittoral ostracod assemblages (Crustacea) from the Caspian Sea: A unique brackish, deep-water environment. Palaeogeography, Palaeoclimatology, Palaeoecology 225:173-186.

Bornemann A., Itterbeeck van J., Schulte P. Steurbaut E., Speijer R.P. 2007. Stable isotope signature $\left(\delta^{13} \mathrm{C}, \delta^{18} \mathrm{O}\right)$ of marine ostracods from the Danian/Selandian boundary (Paleocene, Tunisia). Abstracts. Geophysical Research 9:00078.

Bourdon M. 1962. Methode de degagement des microfossiles par acetolyse a chaud, Compte Rendus Sommleier de Societe Geologique de France. p. 267268.

Breitenbach S.F.M., Bernasconi S.M. 2011. Carbon and oxygen isotope analysis of small carbonate samples (20 to $100 \mu \mathrm{g}$ ) with a GasBench II preparation device. Rapid Commun. Mass Spectrom. 25:1910-1914.

Chivas A.R., De Deckker P., Shelley J.M. 1983. Magnesium, Strontium and Barium partitioning in nonmarine ostracod shells and their use in paleoenvironmental reconstructions - a preliminary study. In: R. F. Maddocks (edit.). Applications of Ostracoda. University of Houston, Geosc. Dep. Houston. p. 238-249.

Corrège T. 1993. Preliminary results of paleotemperature reconstruction using the magnesium to calcium ratio of deep-sea ostracode shells from the Lte Quaternary of Site 822, Leg 133 (Western Coral Sea). Proceedings of the Ocean Drilling Program, Scientific Results 133:175-180.

Corrège T., De Deckker P. 1997. Faunal and geochemical evidence for changes in intermediate water temperature and salinity in the western Coral Sea (northeast Australia) during the Late Quaternary. Palaeogeography, Palaeclimatology, Palaeocology 313:183-205.

Craig H. 1965. The measurement of oxygen isotope paleotemperatures. In: Stable Isotope in Oceanographic Studies and Paleotemperatures (ed. E. Tongiorgi). CNR Lab. Geol. Nucl. Pisa. p. 161-182.

Crowley T.J., North G.R. 1991. Paleoclimatology. Oxford University Press, New York. 349 p.

De Deckker P., Chivas A.R., Shelley J.M.G., Torgersen T. 1988. Ostracod shell chemistry: a new palaeoenvironmental indicator applied to a regressive/transgressive record from the Gulf of Carpentaria, Australia. Palaeogeography, Palaedimatology,
Palaeocology 66:231-241.

Dias-Brito D., Musacchio E.A., Castro J.C., Maranhão M.S.A.S., Suárez J.M., Rodrigues R. 2001. Grupo Bauru: uma unidade continental do Cretáceo do Brasil - concepções baseadas em dados micropaleontológicos, isotópicos e estratigráficos. Revué de Paléobiologie 20(1):245-304.

Durazzi J.T. 1977. Stable Isotope in the Ostracod Shell: A Preliminary Study. Geochimica et Cosmochimica Acta 41:1168-1170.

Emiliani C. 1955. Pleistocene temperatures. Journal of Geology 63:538-578.

Emiliani C. 1966. Isotopic paleotemperatures. Science 154:851-857.

Epstein S., Buchsbaum R., Lowenstam H., Urey H.C. 1951. Carbonate-Water Isotopic Temperature Scale. Bulletins. Geological Society of America 62:417-426.

Epstein S., Mayeda T. 1953. Variation of ${ }^{18} \mathrm{O}$ content of waters from natural sources. Geochimica et Cosmochimica Acta 4:213-224.

Faure G., Mensing T.M. 2005. Isotopes: Principles and Applications. John WileyBlackwell, New Jersey. 3 ed. $928 \mathrm{p}$.

Fischer G., Wefer G. (ed.). 1999. Use of Proxies in Paleoceanography - Examples from the South Atlantic. Springer, Germany. 735 p.

Frenzel P., Boomer I. 2005. The use of ostracods from marginal marine, brackish waters as bioindicators of modern and Quaternary environmental change. Palaeogeography, Palaeoclimatology, Palaeoecology 225:68-92.

Fritz P., Poplawski S. $1974 .{ }^{18} \mathrm{O}$ and ${ }^{13} \mathrm{C}$ in the shells of freshwater molluscs and their environments. Earth and Planetary Science Letters 24:91-98.

Fritz P., Anderson T.W., Lewis C.F.M. 1975. Late-Quaternary climatic trends and history of Lake Erie from stable isotope studies. Science 190:267-269.

Frogley M.R., Griffiths H., Heaton T.H.R. 2001. Historical biogeography and Late Quaternary environmental change of Lake Pamvotis, Ioannina (north-western Greece): evidence from ostracods. Journal of Biogeography 28:745-756.

Grafenstein von U., Erlernkeuser H., Trimborn P. 1999. Oxygen and carbon isotopes in modern fresh-waters ostracod valves: assessing vital offsets and autoecological effects of interest for paleoclimate studies. Paleogeography, Paleoclimatology, Paleoecology 148:133-152.

Grekoff N., 1956. Guide pratrique pour la détermination des ostracodeds post-paléozoïques. Institut Français du Pétrole 95:16-17.

Hoefs J. 2004. Stable Isotope in Geochemistry. SpringerVerlag. Germany. 5 ed. 244 p.

Holmes J.A. 1996. Trace-element and stable-isotope geochemistry of non-marine ostracod shells in Quaternary palaeoenvironmental reconstruction. 
Journal of Paleolimnology 15:223-235.

Holser W.T., Magaritz M., Ripperdan R.L. 1996. Global Isotopic Events. In: Walliser O.H. (edit.). Global Events and Event Stratigraphy in the Phanerozoic. Springer Verlag. p. 63-88.

Ishimura T., Tsunogai U., Gamo T. 2004. Stable carbon and oxygen isotopic determination of submicrogram quantities of $\mathrm{CaCO}_{3}$ to analyze individual foraminiferal shells. Rapid Commun. Mass Spectrom. 18:2883-2883.

Janz H., Venemann T.W. 2005. Isotopic Composition (O, C, Sr and $\mathrm{Nd}$ ) and Trace Element Ratios (Sr/ $\mathrm{Ca}, \mathrm{Mg} / \mathrm{Ca}$ ) of Miocene Marine and Brackish Ostracods from North Alpine Foreland (Germany and Austria) as Indicators for Paleoclimate. Paleogeography, Paleoclimatology, Paleoecology 225:216-247.

Jin Z., Bickle M., Chapman H., Yu J., Greaves M., Wang S., Chen S. 2006. An experimental evaluation of cleaning methods for fossil ostracod $\mathrm{Mg} /$ $\mathrm{Ca}$ and $\mathrm{Sr} / \mathrm{Ca}$ determination. Journal of Paleolimnology 36:211-218.

Keatings K., Heaton T.H.E., Holmes J.A. 2002. The effects of diagenesis on the trace element and stable isotope geochemistry of non-marine ostracod valves. Journal of Paleolimnology 28:245-252.

Keatings K.W., Holmes J.A., Heaton T.H.E. 2006. Effects of pre-treatment on ostracod valve chemistry. Chemical Geology 235:250-261.

Leng M.J., Marshall J.D. 2004. Palaeoclimate interpretation of stable isotope data from lake sediment archives. Quaternary Science Reviews 23:811-831.

Leng M.J., Lamb A.L., Heaton T.H.E., Marshall J.D., Wolfe B.B., Jones M.D., Holmes J.A., Arrowsmith C. 2006. Isotopes in Lake Sediments. In: Leng M.J. (edit.). Isotopes in Palaeoenvironmental Research. Ed. Springer. p. 147-184.

Lethiers F., Crasquin-Soleau S. 1988. Coment extraire des microfossiles à tests calcitiques de roches calcaires dures. Revue de Micropáleontologie 31:56-61.

Li X., Liu W., Zhang P., An Z., Zhang L. 2007. Species, valve size, and pretreatment effects on $\delta^{18} \mathrm{O}$ and $\delta^{13} \mathrm{C}$ values of ostracod valves from Lake Qinghai, Qinghai-Tibet Plateau. Chemical Geo$\log \gamma$ 246:124-134.

Lirer F. 2000. A new technique for retrieving calcareous microfossils from lithified lime deposits. Research Note. Micropaleontology 46(4):365-369.

Lister G.S. 1988. Stable Isotopes from lacustrine ostracoda as tracers for continental palaeoenvironments. In: De Deckker P.; Colin J.-P.; Peypouquet J.-P. (edit.). Ostracoda in the Earth Science. Elsevier Sc. Publishers. p. 201-218.

Martinelli L.A., Ometto J.P., Ferraz E.S., Victoria R.L., Camargo P.B., Moreira M.Z. 2009. Desvendando questões ambientais com isótopos estáveis. São Paulo: Oficina de Textos. $144 \mathrm{p}$.

Marshall J.D. 1992. Climatic and oceanographic iso- topic signals from the carbonate rock record and their preservation. Geological Magazine 129:143160.

Maslin M.A., Swann G.E.A. 2006. Isotopes in Marine Sediments. In: Isotopes in Palaeoenvironmental Research. Ed. Springer. p. 227-290.

Mazzini I. 2005. Taxonomy, biogeography and ecology of Quaternary benthic Ostracoda (Crustacea) from circumpolar deep water of the Emerald basin (Southern Ocean) and the S Tasman Rise (Tasman Sea). Senckenbergiana Maritima 35(1):1-119.

Mc Crea J.M. 1950. On the Isotopic Chemistry of Carbonates and a Paleotemperature Scale. The Journal of Chemical Physics 18:6.

Mischke S., Fuchs D., Riedel F., Schudack M.E. 2002. Mid to Late Holocene palaeoenvironment of Lake Eastern Juyanze (north-western China) based on ostracods and stable isotopes. Geobios 35:99-110.

Mischke S., Zhang C., Borner A. 2008. Bias of ostracod stable isotope data caused by drying of sieve residues from water. Journal of Paleolimnology 40(1):567-575.

Moura J.C., Sousa F.P., Wanderley M.D., Rios-Netto A.M. 1996. Um método alternativo para extração de microfósseis carbonáticos de rochas calcárias, com emprego de ácidos diluídos e tempo de exposição controlado. Anais do XLIX Congresso Brasileiro de Geologia 2:273-275.

Palacios-Fest M.R., Carreño A.L., Ortega-Ramirez J.R., Alvarado-Valdéz G. 2002. A paleoenvironmental reconstruction of Laguna Babícora, Chihuahua, Mexico based on ostracode paleoecology and trace element shell chemistry. Journal of Paleolimnology 27:185-206.

Patience A.J, Kroon D. 1994. Oxygen Isotope Chronostratigraphy. In: Smart P.L., Frances P.D. (edit.). Quaternary dating methods - A user's guide. Quaternary Research Association. London, Technical Guide No4, 10:199-228.

Rodrigues R. 1995. Aplicação da Estratigrafia Química na Identificação de Eventos Paleoceanográficos: Exemplos do Paleozóico ao Cenozóico. In: $1^{\circ}$ Seminário Latino-Americano de Geoquímica Orgânica no Meio Ambiente. Boletim de Resumos Expandidos. p. 91-99.

Rodrigues G.B., Bom M.H., Fauth G. 2012. Recovery of ostracods in Cretaceous dolomitic carbonate: The efficiency of acetolysis. Marine Micropaleontology 92/93:81-86.

Rodrigues G.B., Fauth G., Tomé M.E.T.R., Pereira E., Sial A.N., Viviers M.C. (em preparação). Análises de isótopos estáveis de carbono e oxigênio em ostracodes do Cretáceo do Brasil: um estudo metodológico.

Rollinson H. 1993. Using Geochemical Data: Evaluation, Presentation, Interpretation. Longman Publishing Group, England. 352 p. 
Sakai S. 2006. Micromilling, technique applied to foraminifer tests for sample preparation of geochemical analysis. In: Forams - International Symposium on Foraminifera. Abstracts.

Sakai S., Kodan T. 2011. Micropowder collecting technique for stable isotope analysis of carbonates. Rapid Commun. Mass Spectom. 25:1910-1914.

Serrano, O., Serrano, L., Mateo M.A. 2008. Effects of sample pre-treatment on the $\delta^{13} \mathrm{C}$ and $\delta^{18} \mathrm{O}$ values of living benthic foraminifera. Chemical Geology 257:218-220.

Schudack M.E. 1999. Ostracoda (marine/nonmarine) and palaeoclimate history in the Upper Jurassic of Central Europe and North America. Marine Micropaleotology 37:273-288.

Simstich J., Stanovoy V., Bauch D., Erlenkeuser H., Spielhagen R.F. 2004. Holocene variability of bottom water hydrography on the Kara Sea Shelf (Siberia) depicted in multiple single-valve analyses of stable isotopes in ostracods. Marine Geology 206:147-164.

Skoog D.A., Holler F.J., Nieman T.A. 2006. Princípios de Análise Instrumental. Bookman. 5 ed. 968 p.

Sohn I.G., 1961. Techniques for Preparation and Study of Fossil Ostracods. Q64-Q70. In: Moore R.C. (edit.). Treatise if Invertebrate Paleontology. Part Q, Arthropoda 3, Crustacea, Ostracoda, Geological Society of Am. and University of Kansas Press, Lawrence, $422 \mathrm{p}$.

Sperling M., Wedeab S., Schmiedl G. 2002. Drying of samples may alter foraminiferal isotopic ratios and faunistic composition. Research Note. Micropaleontology 48(1):87-91.

Spötl C., Vennemann T.W. 2003. Continuous-flow isotope ratio mass spectrometric analysis of carbonate minerals. Rapid Commun. Mass Spectrom. 17:1004-1006.

Stuiver M. 1968. Oxygen-18 Content of Atmospheric Precipitation during Last 11,000 Years in the Great Lakes Region. Science 162:994-997.
Tütken T., Vennemann T.W., Janz H., Heizmann E.P.J. 2006. Palaeoenvironment and palaeoclimate of the Middle Miocene lake in the Steinheim basin, SW Germany: A reconstruction from C, O, and $\mathrm{Sr}$ isotopes of fossil remains. Palaeogeography, Palaeoclimatology, Palaeoecology 241:457-491.

Urey H.C. 1947. The Thermodynamic Properties of Isotopic Substances. Journal of the Chemical Society 69:562-581.

Wansard G. 1999. La Géochimie éléments em traces dans la calcite dês ostracodes: príncipes, limites et perspectives de la méthode pour une reconstitution quantifiée des paléoenvironnements. Geobios 32(6):928-933.

Wefer G., Berger W.H., Bijma J., Fischer G. 1999. Clues to Ocean History: a Brief Overview of Proxies. In: Fischer G., Wefer G. (edit.). Use of proxies in Paleoceanography: Examples from de South Atlantic. Springer. 1999. p. 1-68.

White W.M. 2005. Stable Isotopes Geochemistry. In: Geochemistry 9:358-414.

Williams M., Leng M.J., Stephenson M.H., Andrews J.E., Wilkinson I.P., Siveter D.J., Horne D.J., Vannier J.M.C. 2006. Evidence that Early Carboniferous ostracod colonized coastal flood plain brackish water environment. Palaeogeography, $\mathrm{Pa}$ laeoclimatolgy, Palaeoecology 230:299-318.

Xia J., Ito E., Engstrom D.R. 1997a. Geochemistry of Ostracode Calcite: Part 1. An Experimental Determination of Oxygen Isotope Fractionation. Geochimica et Cosmochimica Acta 61(2):337-382.

Xia J., Engstrom D.R., Ito E. 1997b. Geochemistry of Ostracode Calcite. Part 2. The Effects of Water Chemistry and Seasonal Temperature Variation on Candona rawsoni. Geochimica et Cosmochimica Acta 61(2):383-391.

Zhang J., Holmes J.A., Chen F., Qiang M., Zhou A., Chen S. 2009. An 850-year ostracod-shell traceelement record from Sugan Lake, northern Tibetan Plateau, China: Implications for interpreting the shell chemistry in high- $\mathrm{Mg} / \mathrm{Ca}$ waters. Quaternary International 194:119-133. 